\title{
Thematic reviews: Series II-physiological employment standards
}

\author{
Nigel A. S. Taylor
}

Received: 4 April 2013/Accepted: 8 April 2013/Published online: 16 April 2013

(C) Springer-Verlag Berlin Heidelberg 2013

The principal focus of this journal is the dissemination of mechanistic physiological research along with research based upon the application of scientific principles and techniques to solving applied problems, frequently within the occupational and sporting domains. In this, the second series of Invited Thematic Reviews, the emphasis is upon occupational physiology, and the theme is Physiological Employment Standards.

Many organisations require workers to operate within physically demanding environments, and often at high work rates. Such organisations must identify and recruit highly capable and injury-resistant individuals, who will frequently rely upon personal protective clothing, equipment and life-support apparatus during the performance of their jobs. Indeed, technological developments now allow deployment of workers into environments not previously encountered. Whilst this equipment supports survival, it also places a physiological burden upon the worker. Thus, when seeking people to take up these jobs, organisations must consider not just the physiological demands of the job, but also matters relating to duty of care and non-discriminatory work practices. At first sight, these obligations might seem to be at opposite poles. In reality, they are actually different sides of the same coin, for it is the characterisation of these work-related demands that defines the necessary physiological attributes of workers who can then perform these jobs with competence, and without jeopardising the health and safety of themselves, their coworkers or members of the community.

Therefore, the focus of these Thematic Reviews is upon the development, implementation and justification of employment standards within physically demanding occupations. Physiologists were invited to prepare thematic overviews that would introduce readers to the breadth of physiological, applied and legal considerations that influence the development and implementation of valid physiological employment standards. Four Reviews make up this series, and these will be published in two consecutive issues of the journal.

Physiological employment standards I: Occupational fitness standards: objectively subjective?

Physiological employment standards II: Developing and implementing physical employment standards for safetyrelated occupations.

Physiological employment standards III: Physiological challenges and consequences encountered during international military deployment.

Physiological employment standards IV: Integration of women in combat units-physiological and medical considerations.
Communicated by Klaas Westerterp/Håkan Westerblad.

N. A. S. Taylor $(\square)$

University of Wollongong, Wollongong, NSW, Australia

e-mail: nigel_taylor@uow.edu.au 